\title{
Bone marrow drives central nervous system regeneration after radiation injury
}

\author{
Jorg Dietrich, ${ }^{1,2,3,4}$ Ninib Baryawno, ${ }^{1,2,3}$ Naema Nayyar, ${ }^{1,2,3}$ Yannis K. Valtis, ${ }^{1,2,3}$ Betty Yang, ${ }^{1,3}$ Ina Ly, ${ }^{4}$ Antoine Besnard, ${ }^{1,3}$ \\ Nicolas Severe, ${ }^{1,2,3}$ Karin U. Gustafsson, ${ }^{1,2,3}$ Ovidiu C. Andronesi, ${ }^{5}$ Tracy T. Batchelor, ${ }^{4}$ Amar Sahay, ${ }^{1,3}$ and David T. Scadden ${ }^{1,2,3}$ \\ 'Center for Regenerative Medicine, Massachusetts Ceneral Hospital (MCH), Boston, Massachusetts, USA. Department of Stem Cell and Regenerative Biology, Harvard University, Cambridge, Massachusetts, \\ USA. ${ }^{3}$ Harvard Stem Cell Institute, Cambridge, Massachusetts, USA. ${ }^{4}$ Department of Neurology and Division of Neuro-Oncology, MGH, and ${ }^{5}$ Department of Radiology, Athinoula A. Martinos Biomedical \\ Imaging Center, MGH, Harvard Medical School, Boston, Massachusetts, USA.
}

\begin{abstract}
Nervous system injury is a frequent result of cancer therapy involving cranial irradiation, leaving patients with marked memory and other neurobehavioral disabilities. Here, we report an unanticipated link between bone marrow and brain in the setting of radiation injury. Specifically, we demonstrate that bone marrow-derived monocytes and macrophages are essential for structural and functional repair mechanisms, including regeneration of cerebral white matter and improvement in neurocognitive function. Using a granulocyte-colony stimulating factor (G-CSF) receptor knockout mouse model in combination with bone marrow cell transplantation, MRI, and neurocognitive functional assessments, we demonstrate that bone marrowderived G-CSF-responsive cells home to the injured brain and are critical for altering neural progenitor cells and brain repair. Additionally, compared with untreated animals, animals that received G-CSF following radiation injury exhibited enhanced functional brain repair. Together, these results demonstrate that, in addition to its known role in defense and debris removal, the hematopoietic system provides critical regenerative drive to the brain that can be modulated by clinically available agents.
\end{abstract}

\section{Introduction}

Nervous system repair and brain plasticity throughout adult life depend on the function of neural progenitor cells that reside throughout the brain, in white matter tracts, and in specialized neurovascular niches (1-5). Understanding the cellular and molecular factors that orchestrate progenitor cell function is critically important for developing strategies that maintain CNS function and for promoting tissue repair after injury (6-9).

One common form of CNS injury is caused by cranial irradiation, which is well known to damage cerebral white matter, to disrupt the neurovascular niche (10-14), and to result in progressive brain volume loss (15). Importantly, delayed neurologic complications of cranial irradiation have been a major concern for long-term cancer survivors, such as children treated for leukemia or brain tumors $(16,17)$. Debilitating neuropsychiatric syndromes include alterations in memory, executive function, behavior, and mood (16). There are currently no treatments available for patients presenting with such disturbing long-term toxicities, and identification of strategies that minimize neurotoxicity and promote CNS repair following cancer treatment are urgently needed.

Granulocyte CSF (G-CSF) is an endogenous hematopoietic growth factor widely known for its role in stimulating the proliferation and maturation of myeloid progenitor cells and the activation of mature granulocytes (18). It was one of the first

Authorship note: J. Dietrich and N. Baryawno contributed equally to this work. Conflict of interest: The authors have declared that no conflict of interest exists. Submitted: September 14, 2016; Accepted: October 24, 2017.

Reference information: J Clin Invest. 2018;128(1):281-293.

https://doi.org/10.1172/JCI90647. clinically available cytokines and had widespread use in boosting granulocyte counts of patients with either congenital or chemotherapy-induced granulocytopenia (19). Notably, it is also used clinically for the mobilization of primitive hematopoietic stem and progenitor cells (HSPCs) from the bone marrow to the blood where they can be subsequently harvested by leukopheresis for transplantation (20). Interestingly, there are reports of G-CSF serving as a neuronal ligand able to stimulate neurogenesis (21) with positive effects on performance in radial maze experiments in normal rats (22).

We sought to test whether G-CSF can affect repair and neurocognitive function following a common and medically relevant brain injury and to define the cellular participants in any response. We were particularly interested in defining whether hematopoietic cells were directly involved in repair because work by others had shown myeloid cell localization and response to injury in retina (23), brain $(24,25)$, spinal cord (26), and infarcted myocardium (27). In particular, it has been shown that damaged myocardium induces the release of $\mathrm{CCR} 2^{+}$myeloid cells from bone marrow, which in turn is associated with improved cardiac regeneration (28). We therefore asked whether hematopoietic cells could alter the negative impact of irradiation on the central nervous system, on both a structural and functional level. We also sought to determine whether known cytokine regulators of hematopoietic function could modulate the observed effects.

\section{Results}

The cytokine G-CSF enhances progenitor cell proliferation throughout the adult brain following radiation injury. Irradiation was used as a clinically relevant model of diffuse tissue injury widely known to 
A
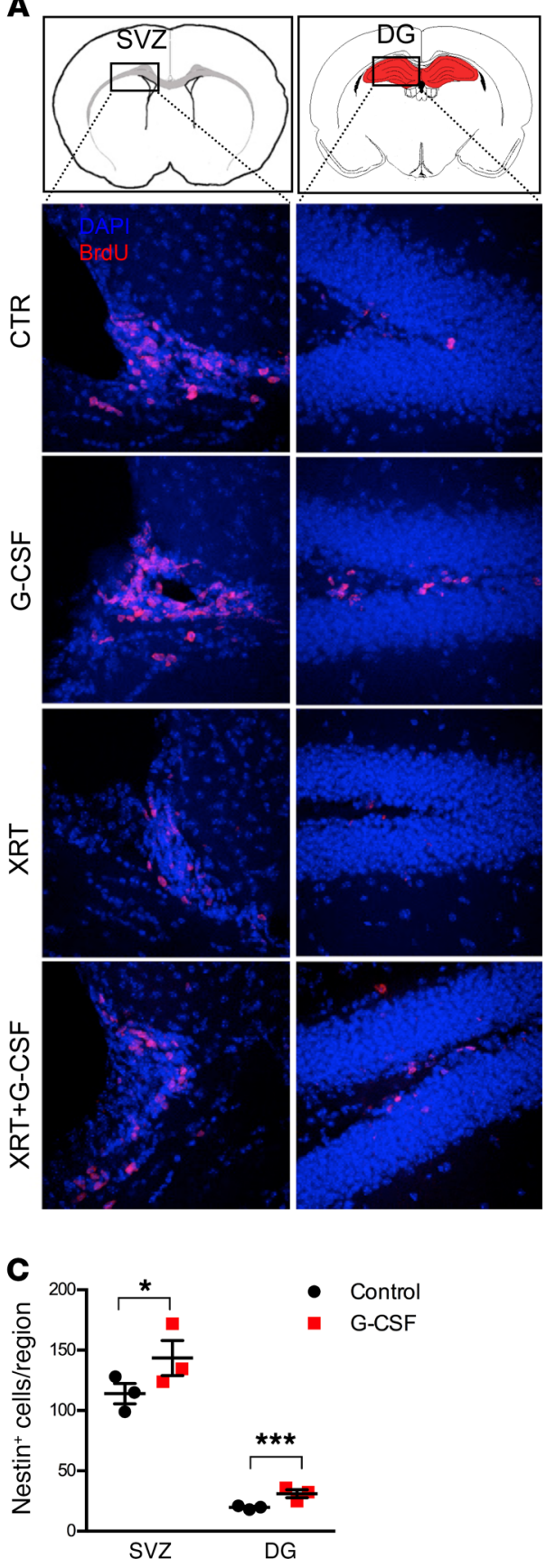

cause increased apoptotic cell death and suppression of progenitor cell proliferation throughout the brain (Supplemental Figure 1; supplemental material available online with this article; https:// doi.org/10.1172/JCI90647DS1). Mice treated with a moderate and sublethal dose (4.5 Gy) of whole-body irradiation were noted to have significantly reduced cell proliferation in germinal zones (subventricular zone [SVZ] and dentate gyrus [DG]; Figure 1, A and B) and white matter tracts (corpus callosum [CC]; Figure 1B). BrdU uptake was reduced by $35 \%$ in the SVZ, by $50 \%$ in the DG, and by more than $60 \%$ in the CC (Figure 1, A and B) 7 days after irradiation. Notably, G-CSF administration $(250 \mu \mathrm{g} / \mathrm{kg})$ increased BrdU uptake and fully rescued the inhibitory effects of radiation on cell proliferation on day 7 after irradiation (Figure 1, A and B). G-CSF
Figure 1. In vivo effects of G-CSF in irradiated mice. (A) Immunohistochemical assessment of $\mathrm{BrdU}^{+}$neural progenitors in the lateral SVZ and DG of the brain from mice treated with PBS or G-CSF or whole-body-irradiated mice (4.5 Gy) treated with PBS or G-CSF. G-CSF was injected on days 1,3 , and 5 after irradiation. At day 5, BrdU was injected, and mice were sacrificed 2 hours after injection. Original magnification: $\times 20$. (B) Quantification of BrdU+ cells from the SVZ, DG, and CC. Asterisks indicate a significant change relative to control. ${ }^{*} P<0.05$; ${ }^{* * *} P<0.001 ;{ }^{* * *} P<0.0001,2$-way ANOVA.

$n=6-8$ independent biological replicates. Data are presented as mean \pm SEM of biological replicates. (C) Quantification of Nestin ${ }^{+}$cells in the brain (SVZ and DG) of nonirradiated mice treated with G-CSF. Asterisks indicate a significant change relative to control. ${ }^{*} P<0.05$; ${ }^{* *} P<0.001$, Student's $t$ test. $n=3$ independent biological replicates. Data are presented as mean \pm SEM of biological replicates.

appeared to enhance BrdU uptake above physiological levels, and we therefore examined the effect of G-CSF, administered by intraperitoneal injection, on nonirradiated animals. A significant increase in the number of Nestin ${ }^{+}$cells, known to represent both neuroglial and mesenchymal progenitor cells in the adult mouse brain, was observed in the lateral SVZ and the DG (Figure 1C). BrdU uptake and doublecortin-positive neuronal progenitor cells were increased in both regions (Supplemental Figure 2, A and B).

To determine whether the radiation-mitigating effects of G-CSF were due to direct or indirect action on brain cells, we performed immunohistochemistry for G-CSF receptor on brain sections of the adult mammalian brain (Figure 2A). G-CSF receptor $^{+}\left(\mathrm{G}-\mathrm{CSFR}^{+}\right)$cells were found in various regions including gray matter and white matter tracts, with the highest numbers of G-CSFR-expressing cells in the choroid plexus ( $~ 95 \%$ of cells) and in regions critical for regeneration, the lateral SVZ and the DG of the hippocampus ( $75 \%$ of cells). G-CSFR ${ }^{+}$cells were also present throughout cerebral white matter ( $~ 50 \%$ of cells) and in the cerebral cortex ( $25 \%$ of cells) (Figure 2, B and C). CD140b ${ }^{+} \mathrm{CD} 31^{-}$neuroglial and mesenchymal progenitor cells isolated by flow cytometry and characterized by quantitative PCR (qPCR) (Supplemental Figure 3, A and B) were noted to express the receptor for G-CSF and Nestin (Figure 2D) as well as EGF and PDGF- $\beta$, both important mitogens for neuroglial progenitor cells (Supplemental Figure 3B). Cells proliferate in response to G-CSF in a dose-dependent manner in vitro (Figure 2E) and in vivo (Figure 1C and Supplemental Figure 2). These results are consistent with, but not definitive of, a direct effect of G-CSF on cells in the brain. We therefore sought to determine whether indirect effects mediated by bone marrow participate in the structural and cell-biological findings identified following G-CSF treatment.

Circulating bone marrow-derived G-CSFR-positive cells are critical to brain repair mechanisms after radiation injury. To examine the influence of bone marrow-derived cells on the observed G-CSFrelated effects, we used a G-CSFR ${ }^{-/-}$mouse model in combination 
A
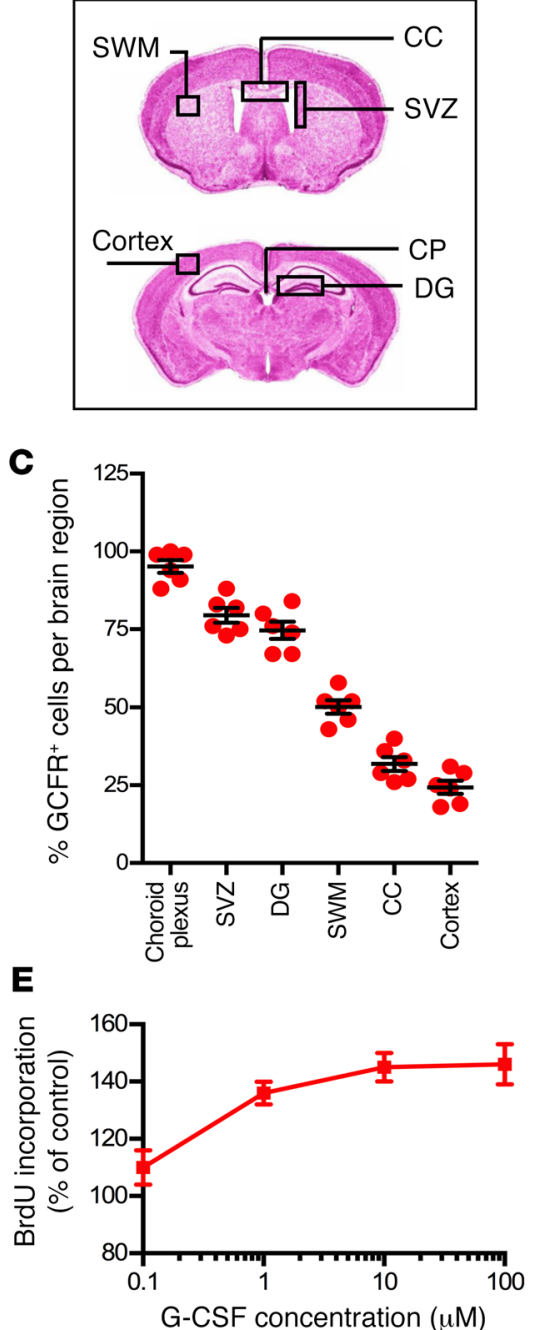

B
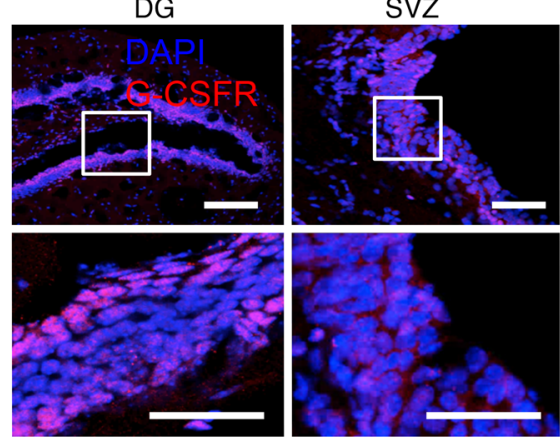

D
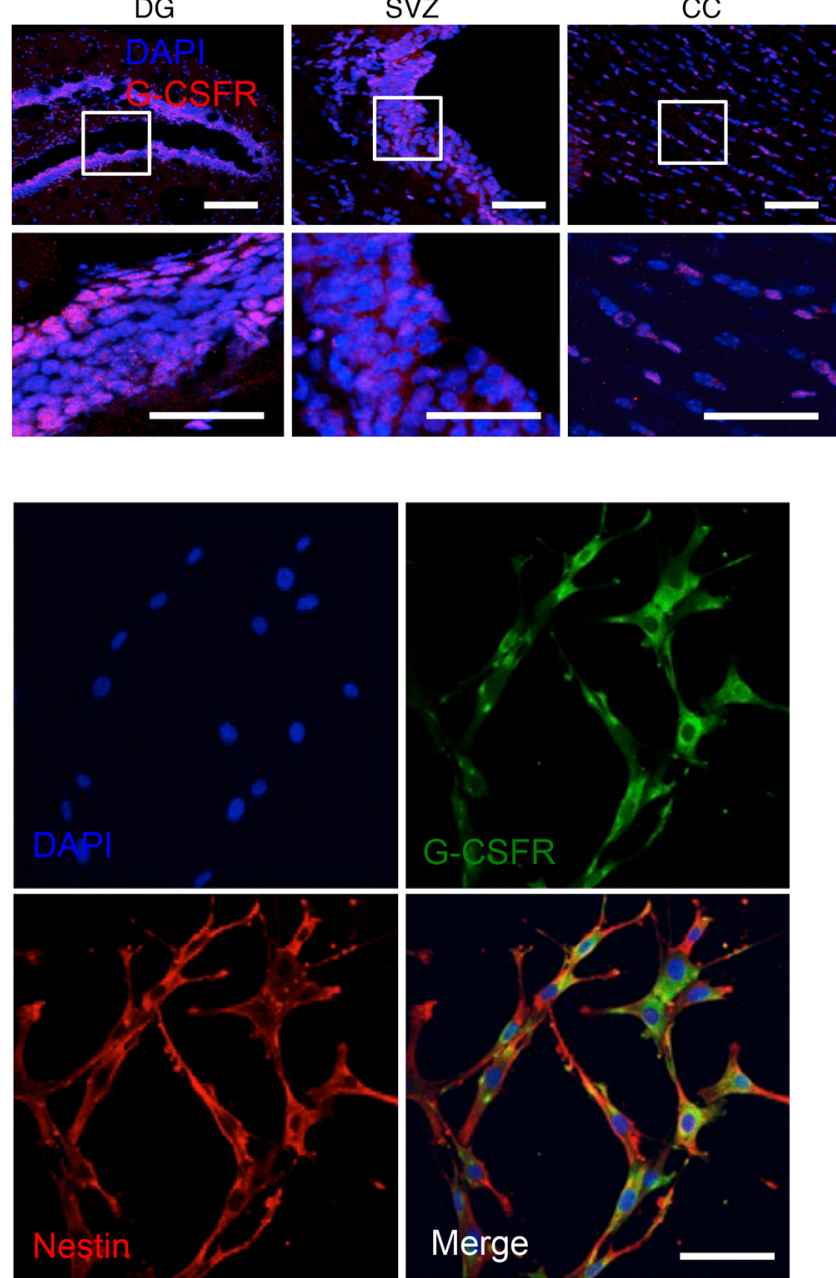

SWM

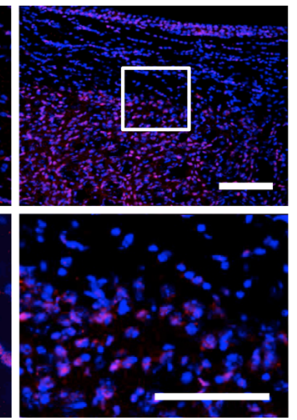

Figure 2. Characterization of G-CSFR expression in the adult CNS. (A) CNS regions assessed for G-CSF receptor expression. (B) G-CSF receptor expression in different areas of the CNS as shown by immunofluorescence. Original magnification, $\times 20$ (upper panels); $\times 40$ (lower panels). (C) Quantification of G-CSF receptor-positive cells from B. $n=6$ independent biological replicates. Data are presented as mean \pm SEM of biological replicates. (D) Characterization of cultured Nestin ${ }^{+}$cells. Immunofluorescence staining of cultured Nestin ${ }^{+}$cells for G-CSF receptor (green) and Nestin (red). Original magnification, $\times 40$. (E) Cultured Nestin ${ }^{+}$cells in the presence of increasing concentrations of G-CSF, showing an increase of cell proliferation as measured by BrdU uptake in a dosedependent manner in the range of $1-10 \mu \mathrm{M}$. Cells were kept in culture for 2 to 3 days, and growth kinetics and the number of BrdU ${ }^{+}$cells (shown as \%BrdU ${ }^{+}$ cells from controls) were analyzed in the presence of increasing G-CSF concentrations in 4 independent experiments. SWM, subcortical white matter.

with bone marrow transplantation and radiation injury (Figure 3A). Specifically, mice were transplanted with either WT or G-CSFR ${ }^{-/-}$ bone marrow cells. All animals received 9.5 Gy of whole-body irradiation to enable engraftment of the transplanted bone marrow. Following an interval of 8 to 12 weeks to enable cellular engraftment (Supplemental Figure 4), mice were treated with an additional $4.5 \mathrm{~Gy}$ of focal brain radiation with or without G-CSF using a lead shield (Supplemental Figure 5). Cell proliferation was assessed in white matter tracts (CC) and neurogenic niches (SVZ and DG) using BrdU incorporation assays. Notably, BrdU ${ }^{+}$cells were decreased in cerebral white matter, SVZ, and DG of mice transplanted with

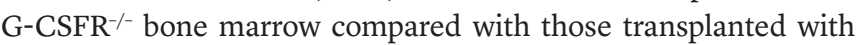
WT bone marrow (Figure 3B). This difference was observed under conditions in which no exogenous G-CSF was administered and in animals given additional G-CSF. Therefore, the G-CSFR status of bone marrow-derived cells determined $\mathrm{BrdU}^{+}$responses to radiation injury and could be modulated by administration of G-CSF only if the animals had a hematopoietic system capable of responding to it. While a contribution of nonhematopoietic cells in our cell transplant models cannot be ruled out, the efficiency of transplant of anything other than hematopoietic cells in similar systems is extremely low $(29,30)$. The data therefore strongly support a role for bone marrow-derived G-CSFR ${ }^{+}$cells in the salutary effect of $\mathrm{G}-\mathrm{CSF}$ treatment following brain irradiation.

Neuroprotective effects of G-CSF are enhanced in mice spared from bone marrow irradiation. Based on the above findings (Figure $3 \mathrm{~B}$ ), we tested the effects of G-CSF on cell proliferation and neurogenesis in germinal zones and white matter tracts in mice exposed to either focal brain or whole-body irradiation. In an attempt to determine whether focally irradiated mice would demonstrate 
A
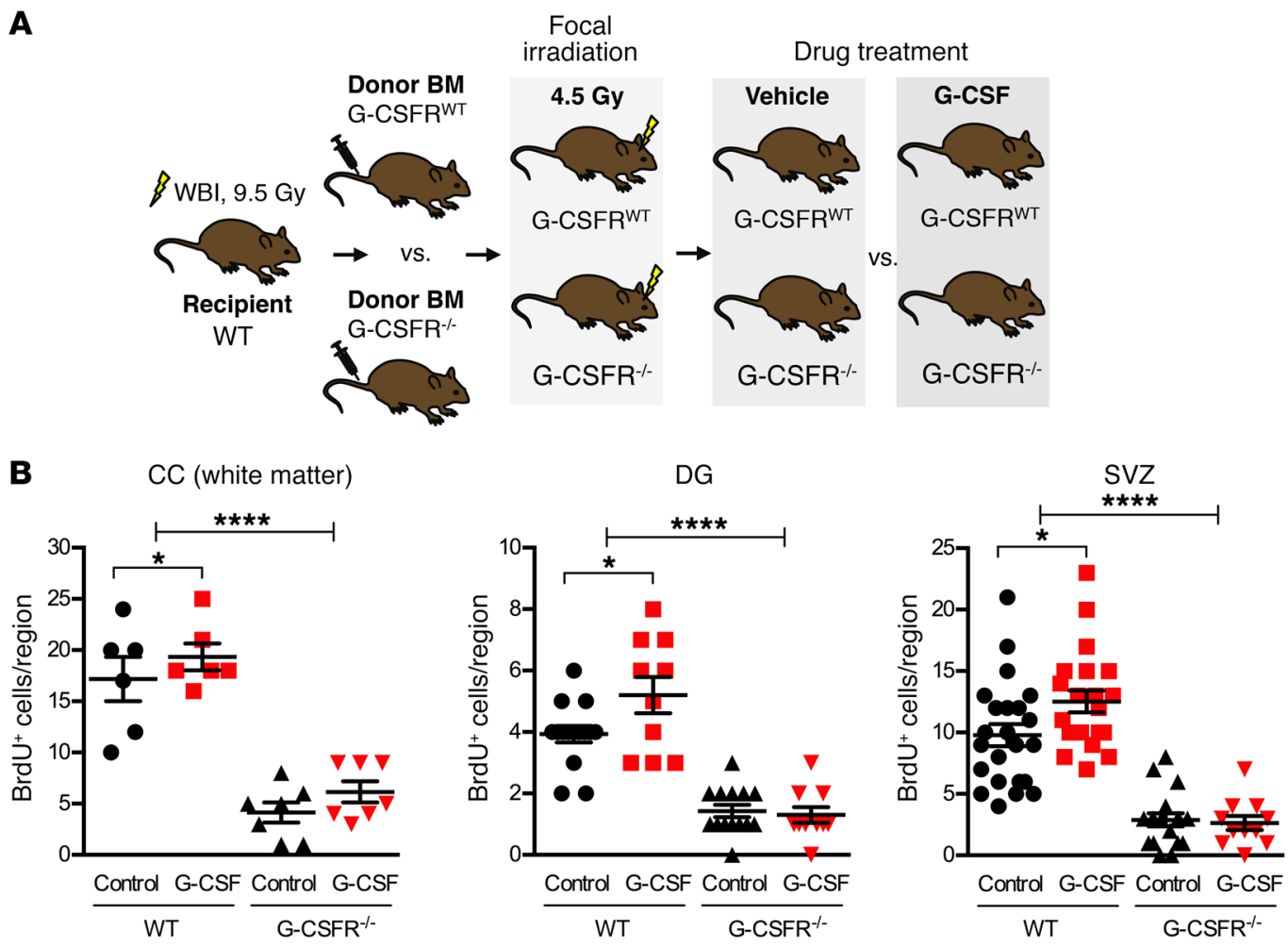

Figure 3. Bone marrow-derived G-CSFR+ cells are critical for brain regeneration after radiation injury. (A) Schematic diagram of the experimental layout. Mice were treated with whole-body irradiation ( $9.5 \mathrm{~Gy}$ ) and transplanted the next day with either WT or G-CSFR ${ }^{-/-}$bone marrow cells. After reconstitution of the blood (Supplemental Figure 4), mice underwent focal brain irradiation (4.5 Gy) followed by G-CSF treatment on days 1, 3, 5, 7, 14, and 21 after irradiation. BrdU was injected on days 21, 28, and 47 after irradiation. Mice were sacrificed on day 47, 4 hours after the last BrdU injection. (B) Quantification of $\mathrm{BrdU}^{+}$progenitors in the cerebral white matter and germinal zones of the brain. Asterisks indicate a significant change relative to control. ${ }^{*} P<0.05$; ${ }^{* * * *} P<0.0001,1$-way ANOVA. $n=6$ independent biological replicates. Data are presented as mean \pm SEM of biological replicates.

more efficient repair in the setting of intact bone marrow, mice were treated with either whole-body irradiation (sublethal dose of $4.5 \mathrm{~Gy}$ ) or focal brain irradiation (fractionated dosing, 3 fractions of $2 \mathrm{~Gy}$ ) or were left untreated (control group). To allow for sufficient time for newly generated cells to differentiate into mature neurons, adult mice in each group were treated with G-CSF over the course of 5 weeks until sacrifice for immunohistochemical analysis. Control mice in each group received saline injections. Cell proliferation was assessed by BrdU incorporation in white matter tracts (CC), SVZ, and DG. In addition, we used the mature neuronal marker NeuN (31) in combination with BrdU labeling to evaluate for potential effects on neurogenesis 5 weeks after radiation exposure with or without G-CSF treatment.

While both whole-body and focal brain irradiation resulted in increased cell proliferation at the 5-week time point, a known compensatory repair mechanism after diffuse cell injury, the effects were most pronounced in mice treated with focal brain irradiation and exposed to G-CSF (Figure 4, A and B). The most striking effects of G-CSF were seen in the number of proliferating cells in cerebral white matter tracts. BrdU ${ }^{+}$cells in cerebral white matter (CC) exclusively colabeled with the oligodendroglial marker Olig2 (Supplemental Figure 6) in support of enhanced gliogenesis in white matter tracts. In G-CSF-exposed animals, we observed an increase in the total number of $\mathrm{NeuN}^{+} \mathrm{BrdU}^{+}$cells, although the relative number of $\mathrm{NeuN}^{+} \mathrm{BrdU}^{+}$cells remained unchanged in all groups, supporting a global neuroprotective effect of G-CSF as opposed to a selective effect on neurogenesis alone.

To further support our findings of a key role of G-CSF signaling in response to brain injury, we measured G-CSF protein levels in serum of mice exposed to brain irradiation and found significantly increased levels after irradiation (Supplemental Figure 7).

Bone marrow-derived cells with a monocyte/macrophage and microglial phenotype home to the irradiated brain and can be identified in perivascular and parenchymal brain regions. To assess the cellular basis for the effects of G-CSF, we tested whether bone marrow-derived cells are able to home to the brain in the setting of radiation injury. Whole bone marrow cells from $\mathrm{GFP}^{+}$mice expressing GFP under the human ubiquitin $\mathrm{C}$ promotor (UBIGFP) were transplanted $\left(1 \times 10^{6}\right.$ cells/mouse $)$ into either wholebody-irradiated (9.5 Gy) WT recipients or nonirradiated controls by tail-vein injection (Figure 5A). Four weeks after irradiation, mice were sacrificed and brains analyzed by immunohistochemistry for evidence of $\mathrm{GFP}^{+}$donor cells.

Notably, $\mathrm{GFP}^{+}$cells could be identified in abundance in irradiated animals in choroid plexus, meningeal and perivascular locations, and in brain parenchyma with distinct phenotypes and morphology (Figure 5, A and B). The majority of $\mathrm{GFP}^{+}$cells in the choroid plexus and cortex stained positive for the microglia marker Iba-1 (Figure 5, C and D), suggesting a monocyte/macrophage origin, whereas many $\mathrm{GFP}^{+}$cells in the perivascular location, white 
A
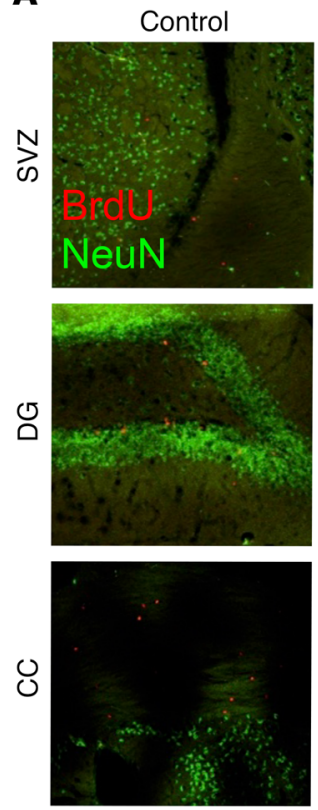

Control + G-CSF
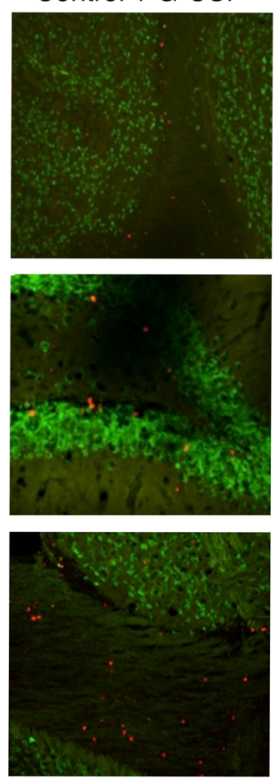

Whole-body XRT
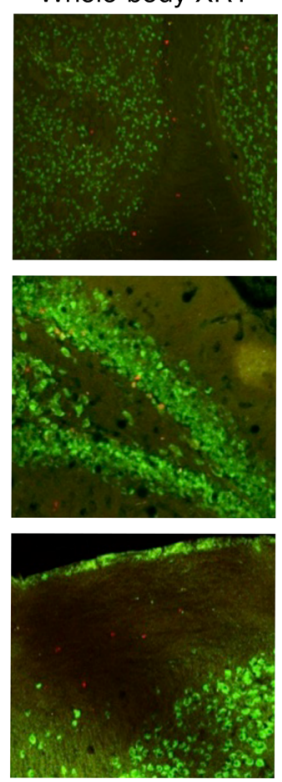

Whole-body XRT + G-CSF
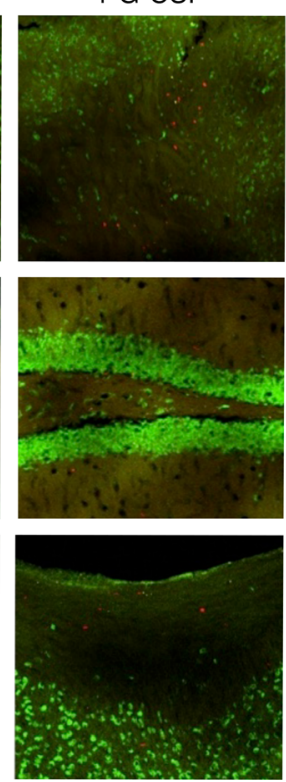

Focal-brain XRT
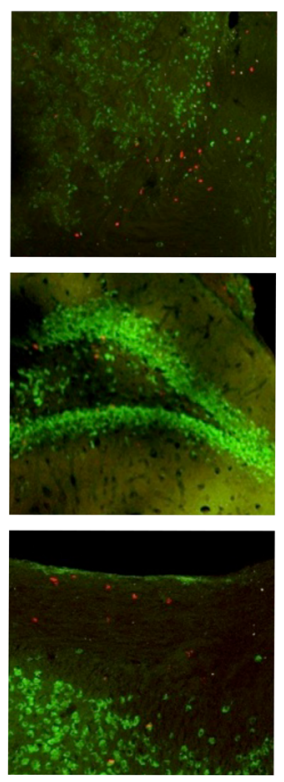

Focal-brain XRT $+\mathrm{G}-\mathrm{CSF}$
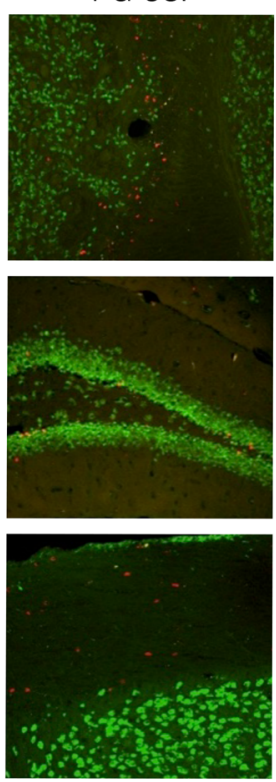

B

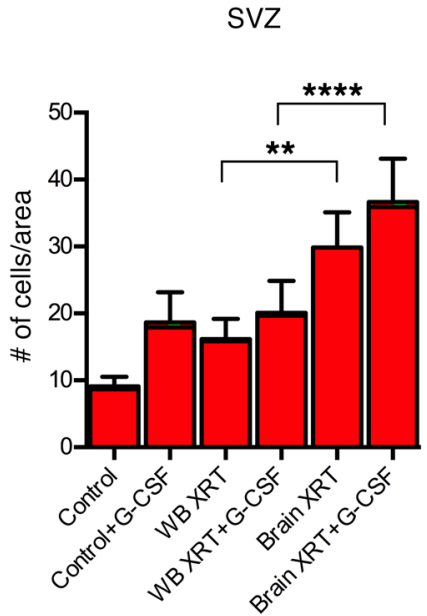

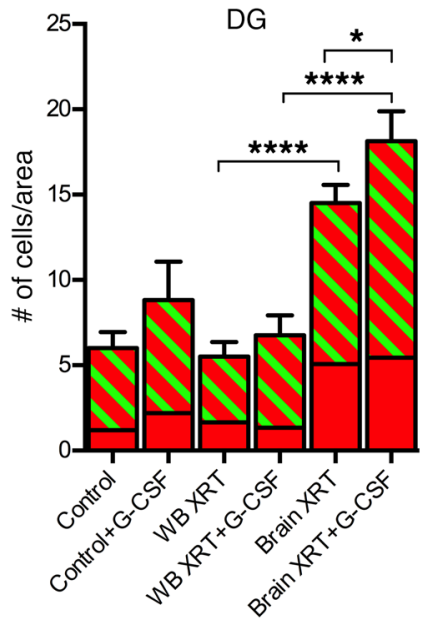

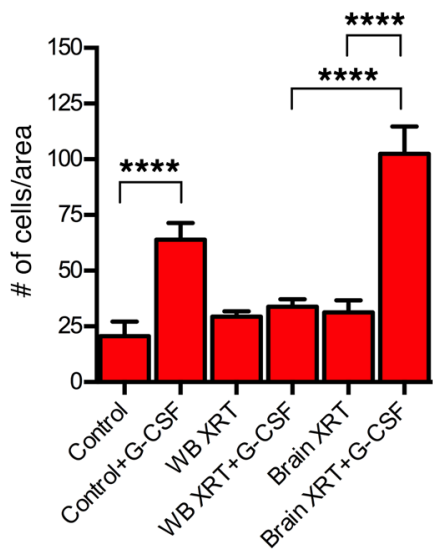

$\mathrm{BrdU}^{+}$

$\% \mathrm{NeuN}^{+}$of BrdU

Figure 4. Regenerative capacity of G-CSF comparing whole-body irradiation vs. focal-brain irradiation. Mice were exposed to either whole-body (4.5 Gy) or focal-brain irradiation ( $3 \times 2$ Gy) or left untreated. On the next day, mice were treated by vehicle control or G-CSF (on days 1-5) and subsequently were treated weekly until sacrifice at day 35 after irradiation. All mice were injected with BrdU on days 1-5. Original magnification: $\times 10$. (A) Immunohistochemical assessment of BrdU-positive (red) and NeuN-positive (green) cells in the SVZ, DG, and CC. (B) Quantification of BrdU ${ }^{+}$and NeuN ${ }^{+}$cells. Asterisks indicate a significant change relative to control. ${ }^{*} P<0.05 ;{ }^{* *} P<0.01$; ${ }^{* * *} P<0.0001,1$-way ANOVA. $n=3$ independent biological replicates. Data are presented as mean \pm SEM of biological replicates.

matter tracts, and germinal zones were Iba-1 negative (Figure 5, C and D). Importantly, only rare $\mathrm{GFP}^{+}$cells were identified in nonirradiated animals, in which occasional $\mathrm{GFP}^{+}$cells were identified in the choroid plexus, but not in other brain regions (Figure 5A).

To further study whether such effects were transient or permanent, we performed an additional experiment in which mice were treated in a fashion similar to that shown in Figure 5, but were sacrificed at 2 and 8 weeks after irradiation to study the cellular effects over time (Figure 6). Location, quantity, morphology, and phenotype of bone marrow-derived $\mathrm{GFP}^{+}$cells were analyzed in various brain regions. We found that the total number of $\mathrm{GFP}^{+}$cells in all brain regions analyzed increased over time (comparing 2 weeks and
8 weeks after transplantation), with the most significant increases observed in CC (white matter), DG (neurogenic region), SVZ (neurogenic and gliogenic region), and cortex (gray matter region), supporting the notion of a durable rather than transient effect (Figure 6, $\mathrm{A}$ and $\mathrm{B})$. The morphology of $\mathrm{GFP}^{+}$cells changed considerably over time, with a significantly increased number of cell processes and an augmented branched morphology (Figure 6, C and D), suggestive of in vivo cell maturation as well as integration and interaction of $\mathrm{GFP}^{+}$ cells with the existing cellular microenvironment.

To further examine the phenotype of $\mathrm{GFP}^{+}$cells, we colabeled $\mathrm{GFP}^{+}$cells with markers for glial (GFAP, Olig2), neuronal (Doublecortin, NeuN, B-III tubulin), microglial (Iba-1), and mono- 
A
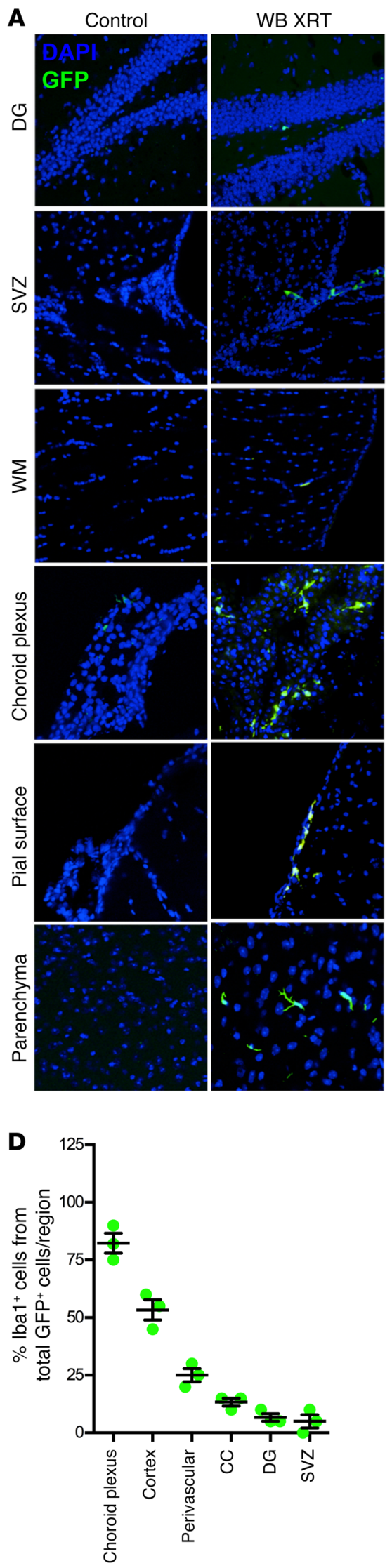

B
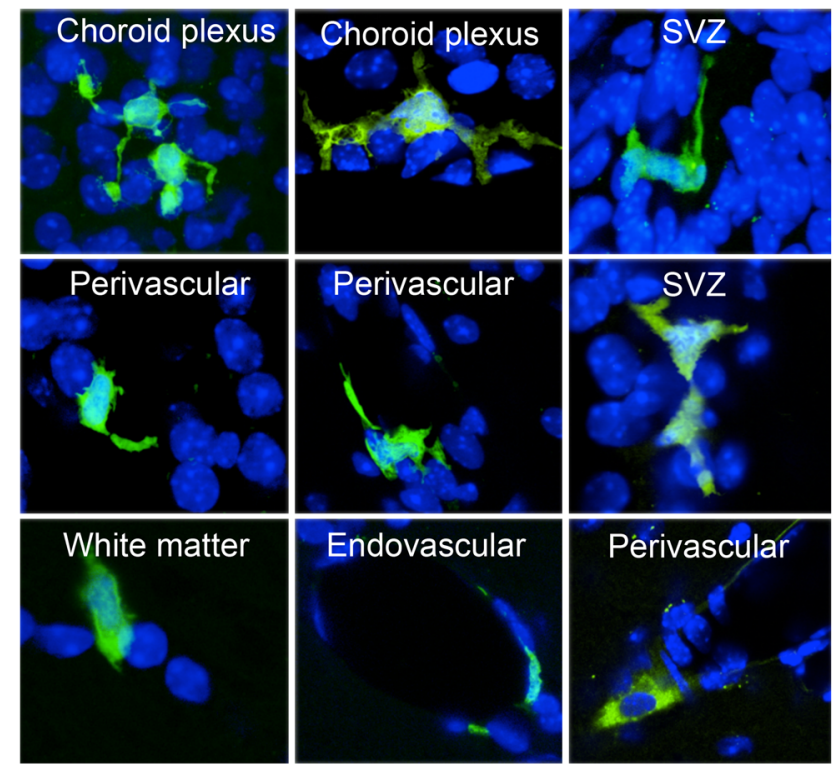

Endovascular
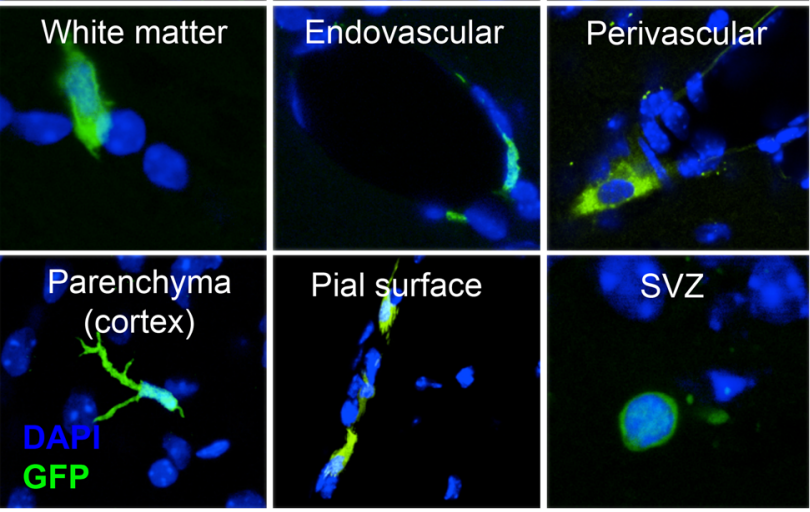

C
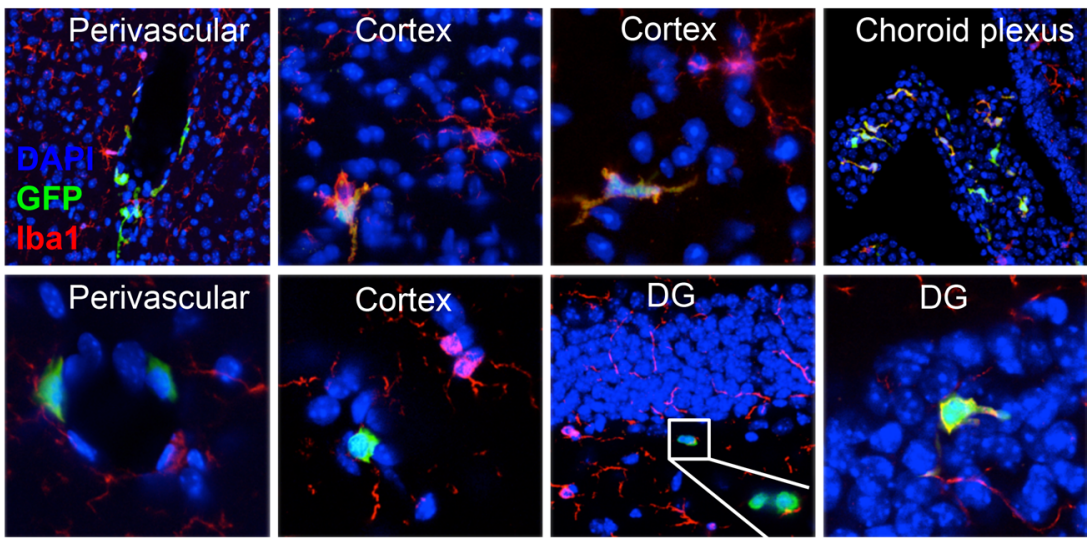

Figure 5. Identification, quantification, and phenotype of transplanted GFP+ bone marrow cells in the mouse brain following irradiation over time. (A-D) Identification of transplanted $\mathrm{GFP}^{+}$bone marrow cells in the murine CNS 4 weeks after transplantation. (A and B) Immunohistochemical assessment of different brain regions from mice transplanted with GFP+ bone marrow cells (transgenic UBI-GFP reporter mouse). Whole bone marrow cells from UBI-CFP mice were harvested and transplanted $\left(1 \times 10^{6}\right.$ cells/mouse) into either whole-body-irradiated (9.5 Gy) recipients or nonirradiated controls by tail-vein injection. Four weeks after irradiation, mice were sacrificed and brains sectioned for immunohistochemical evidence of GFP+ donor cells. Original magnification, $\times 10$ (A); $\times 40$ (B). (C) CNS regions assessed by immunofluorescence for $\mathrm{GFP}^{+}$bone marrow cells, colabeled with the microglial marker Iba-1. Original magnification, $\times 20$, except $\times 10$ for perivascular region upper panel, choroid plexus upper panel, and DG lower panel. (D) Quantification of Iba- $1^{+} \mathrm{CFP}+$ cells from C. $n=3$ independent biological replicates. Data are presented as mean \pm SEM of biological replicates. 
cyte-macrophage (F4/80) cells. We found that the majority of $\mathrm{GFP}^{+}$cells showed a phenotype consistent with monocyte/macrophages (as labeled by F4/80) (Figure 6, E and G) and microglial cells (as labeled by Iba-1) (Figure 5C and Figure 6G). While a significant proportion of $\mathrm{GFP}^{+}$cells also colabeled with B-III tubulin (Figure 6, F and G), none of the $\mathrm{GFP}^{+}$cells colabeled with the neuronal markers NeuN and doublecortin or the glial markers GFAP and Olig2 (data not shown).

G-CSF improves neurocognitive function following brain irradiation. To assess whether the G-CSF-mediated neuroprotective effects were associated with functional consequences in a clinically relevant fractionated radiation model, irradiated mice (with and without G-CSF exposure) were tested in a series of neurocognitive and neurobehavioral assays commonly used to evaluate learning and memory function $(32,33)$.

In the contextual fear-conditioning assay, mice learn to predict an aversive stimulus in the context of a specific environment and demonstrate "freezing" as a measure of fear conditioning and learning function. This learning and memory test is considered to involve hippocampal, amygdala, cingulate, and frontal network systems. Irradiated mice that had been treated with G-CSF were cued to an unwanted stimulus similarly to irradiated control mice (that were not exposed to G-CSF). G-CSF-treated mice, however, showed significantly greater freezing behavior in the conditioned context (context A), but not in a dissimilar context (context B), suggestive of improved memory function (Figure 7A).

The Morris water maze assay, one of the most effective testing paradigms for assessing hippocampus-dependent spatial learning and memory, relies on cues to navigate from start locations around the perimeter of an open swimming arena to locate a submerged escape platform. Spatial learning is assessed during repeated trials, and impairments in spatial learning and memory are enhanced in reversal trials. G-CSF-treated mice demonstrated a slightly improved tendency for enhanced spatial reference learning, but more importantly, showed significant improvement in memory retrieval in the reversed learning task - which requires spatial memory recall - suggestive of improved memory function (Figure 7B).

Finally, we found that G-CSF mice also showed a tendency for decreased anxiety-like behavior in the elevated plus maze (EPM), light/dark box (LDB), and open-field (OF) assays (Supplemental Figure $8, \mathrm{~A}-\mathrm{C})$. Conceptually, these tests are based on the innate aversion of mice to light-exposed areas and on the spontaneous exploratory behavior in response to mild stressors, such as novel environment and light. While the total number of entries in the open arm of the EPM testing was not different between both groups, G-CSF-treated mice spent significantly longer distances in the open and light-exposed arms compared with untreated mice (Supplemental Figure 8A), suggesting a less anxious phenotype. In the LDB test (Supplemental Figure 8B), G-CSF-treated mice demonstrated longer distances, remained for longer times in the light compartment, and engaged in a greater number of entries into the light compartment when compared with saline-treated controls. Consistent with these observations, G-CSF-exposed mice also spent more time and a longer distance in the light-exposed OF test (Supplemental Figure 8C).

Together, these data provide evidence for improved learning and memory function and reveal a tendency for decreased anxiety-like behavior in irradiated mice treated with G-CSF.
$G$-CSF restores white matter disruption caused by irradiation. Radiation is well known to cause significant damage to cerebral white matter $(34,35)$ and can be associated with progressive and debilitating neurocognitive dysfunction and memory impairment that usually evolves over the course of years after treatment (16).

To test the hypothesis of whether the neuroprotective effects of G-CSF on cell proliferation and cognitive function were associated with radiographically measurable long-term effects on brain structure, we used cranial MRI in mice previously exposed to brain irradiation and treated with and without G-CSF. Imaging done 14 months after brain irradiation, a time course comparable to the evolution of white matter disease in patients, revealed a significant reduction of cerebral white matter in control mice (Figure 7C). Most importantly, irradiated mice treated with G-CSF showed evidence of restoration of white matter density comparable with values obtained from control mice that were not exposed to any prior irradiation. Both manual and automated segmentation analyses confirmed a statistically significant restoration of total cerebral white matter volume following G-CSF treatment (Figure 7C and Supplemental Figure 9, A and B, here shown for CC - one the largest white matter tracts). Therefore, G-CSF alters functional and neuroanatomic features of radiation injury of the brain.

\section{Discussion}

We here present evidence that G-CSF contributes to both structural and functional brain repair following radiation injury. G-CSF stimulates proliferation of neuro-glial progenitor cells, improves neurocognitive function, and restores cerebral white matter damage secondary to irradiation injury.

Using a G-CSF receptor knockout mouse model in the setting of bone marrow transplantation and radiation injury, we found that bone marrow-derived G-CSF-responsive cells are a critical component of endogenous brain repair following radiation injury. While the exact mechanisms on how G-CSF-responsive cells from the bone marrow modulate brain regeneration remain to be characterized, our data suggest that both direct effects (on resident brain cells) and indirect effects (on the cellular microenvironment on neurovascular niches) are likely to play a role.

We here demonstrate that bone marrow-derived cells of monocyte-macrophage origin effectively home to the central nervous system after irradiation injury, mature, and integrate into the existing cellular microenvironment in various brain regions where they durably reside. While the majority of cells retained a monocyte/macrophage and microglial phenotype, a substantial number of bone marrow-derived cells also colabeled with B-III tubulin. B-III tubulin is considered a neuronal marker by many investigators, but others have shown that it is a nonspecific marker also expressed in nonneuronal cells, such as in bone marrow-derived hematopoietic and mesenchymal cells (36-39). As none of the bone marrow-derived cells colabeled with other neuronal markers, we caution that B-III tubulin may not be indicative of a neuronal identity in the context of our study.

Radiation is well known for its neurotoxic effects, including alteration of neural progenitor cell function, increased apoptotic cell death throughout the brain (including white matter), and impaired hippocampal function $(10,12,40,41)$, a brain area critically relevant for maintenance of learning and memory and regulation of mood and anxiety (42-49). 
A

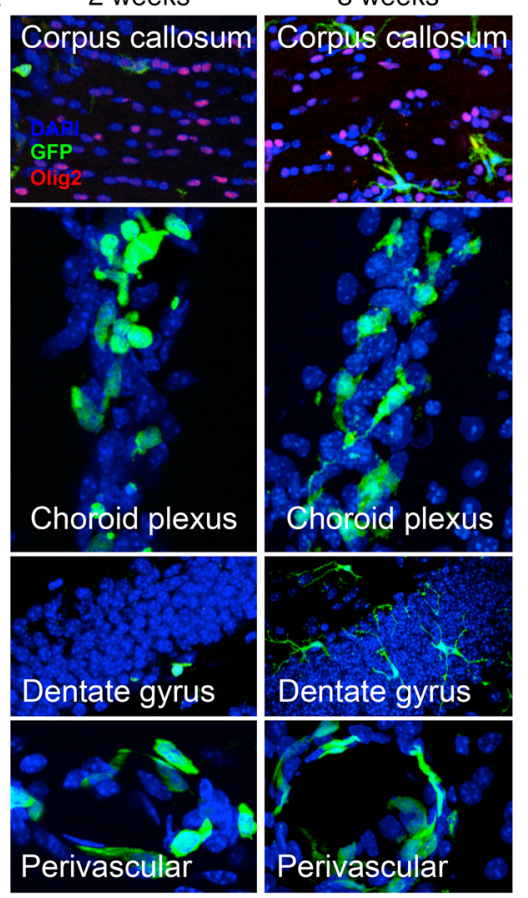

B

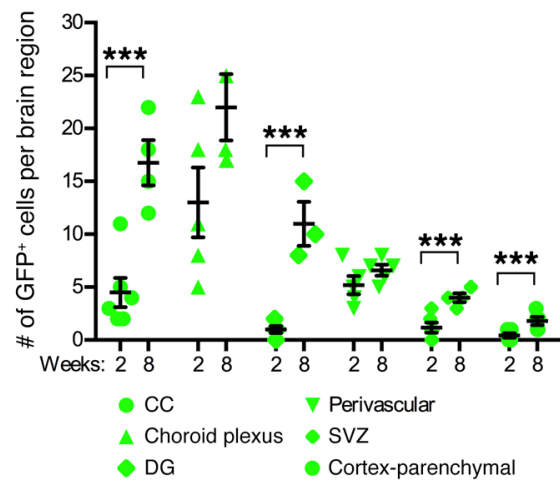

E

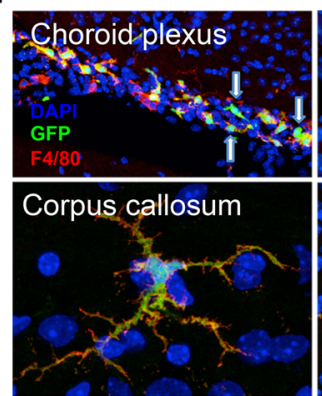

$\mathbf{F}$

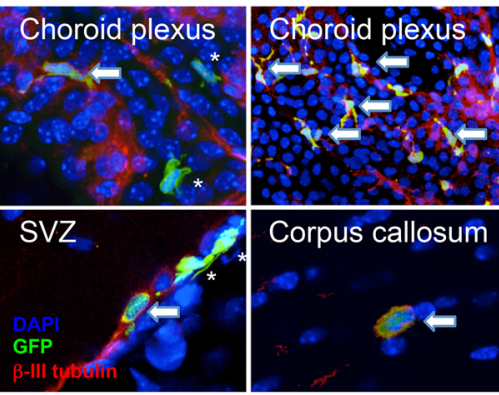

C

2 weeks
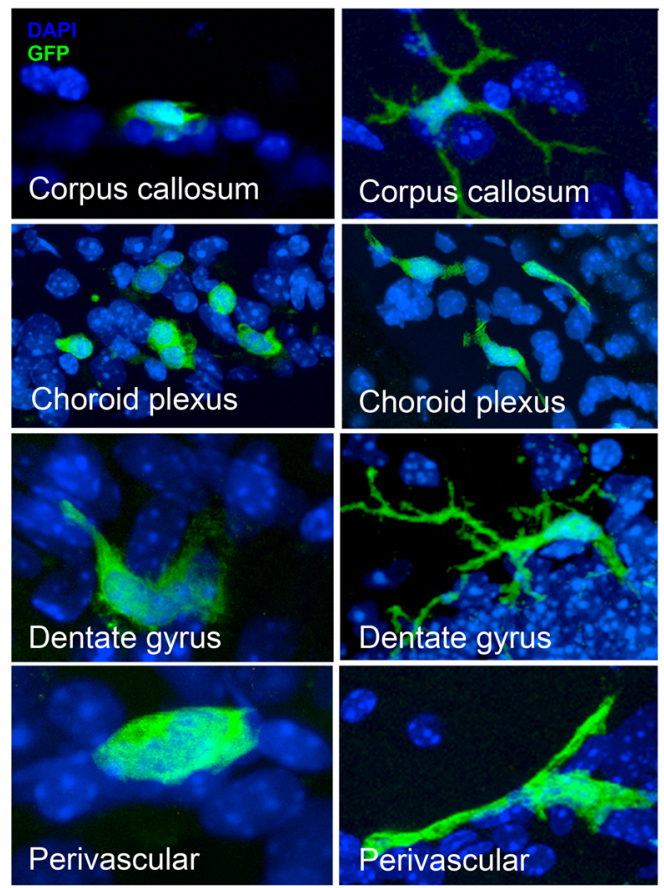

D
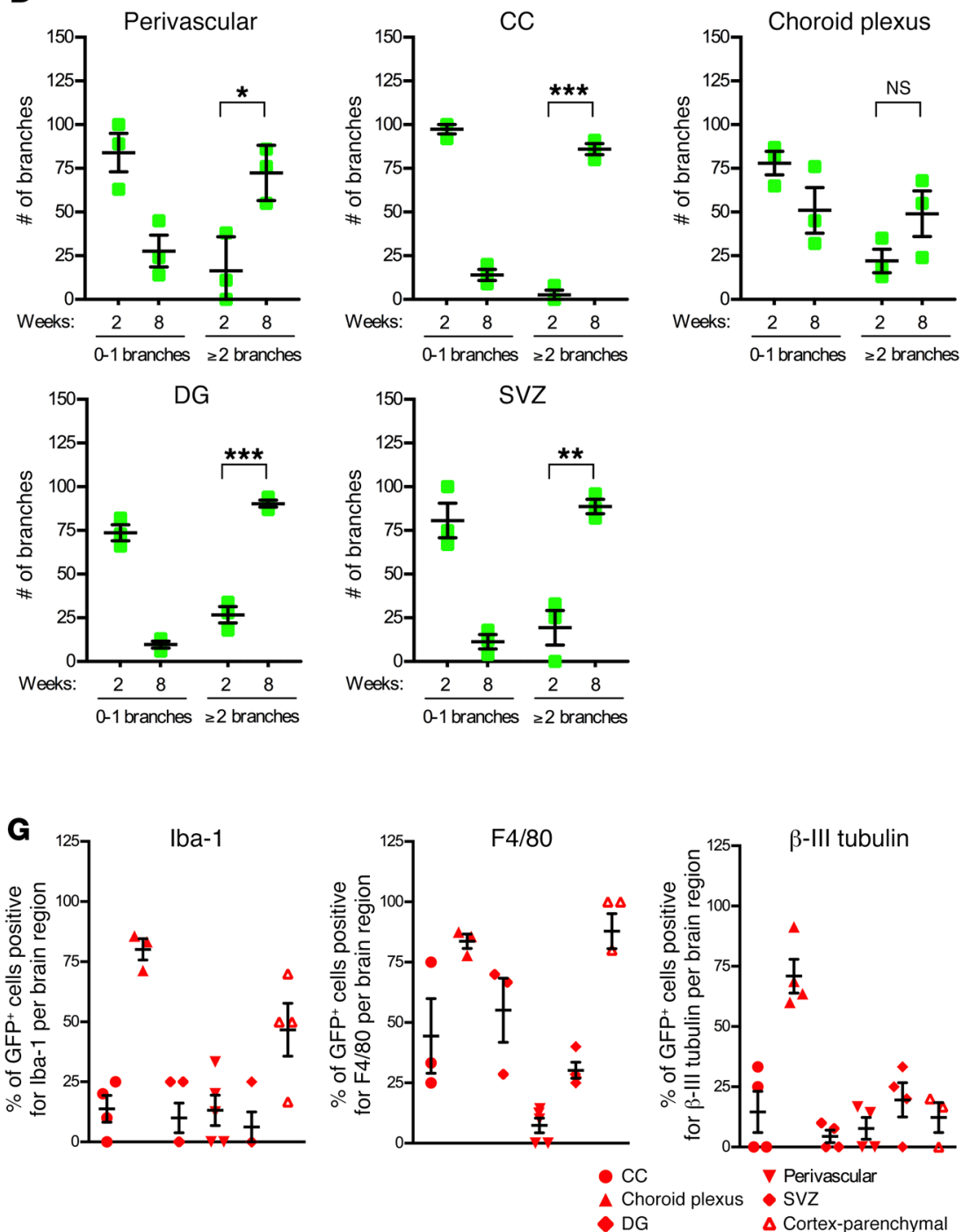
Figure 6. Immunohistochemical assessment of different brain regions from mice transplanted with GFP+ bone marrow cells (transgenic UBI-GFP reporter mouse) and assessed $\mathbf{2}$ and $\mathbf{8}$ weeks after irradiation. (A) Mice were sacrificed and brains sectioned for immunohistochemical evidence of GFP ${ }^{+}$donor cells. Original magnification, $\times 20$ (CC and DC); $\times 40$ (choroid plexus and perivascular region). $n=3$ independent biological replicates. Data are presented as mean \pm SEM. (B) Quantification of GFP+ cells in different brain regions evaluated at 2 and 8 weeks after irradiation showing a significant increase in the total number of GFP+ ${ }^{+}$cells after 8 weeks in CC, DG, SVZ, and cortex. (C and D) Significant change in morphology of GFP+ cells over time with signs of cellular maturation and increase in branched morphology in various regions. Original magnification, $\times 40$, except $\times 60$ in DG and perivascular region, left-sided panel. (E-G) Phenotypical analysis of GFP+ cells demonstrate that the majority of cells colabel the microglial marker Iba-1 (see Figure 5C) and the monocyte-macrophage marker F4/80. Upper panel original magnification: $\times 20$. Lower panel original magnification: $\times 40$ (E). In addition, many GFP' cells colabeled with B-III tubulin Upper panel original magnification: $\times 20$. Lower panel original magnification: $\times 40$ (F). (G) Quantification of GFP+ cells colabeling with Iba-1, F4/80, and B-III tubulin. Asterisks indicate a significant change relative to control. ${ }^{*} P<$ 0.05 ; ${ }^{*} P<0.01 ;{ }^{* * *} P<0.001,1$-way ANOVA. $n=3$ mice/group. Data are presented as mean \pm SEM of biological replicates.

While some previous observations indicate that exposure to G-CSF prior to irradiation injury can mitigate the harmful effects of irradiation (50), the data presented here indicate that G-CSF or G-CSF-responsive bone marrow-derived cells serve as critical mediators of repair and thereby might provide therapeutic value in the setting of radiation-induced brain injury. The impact observed in our study involved progenitor cell populations in the adult mouse brain and was associated with improved functional attributes of clinical relevance for patients.

While it remains unknown whether bone marrow-derived cells are required to migrate to the brain in order to modulate brain function or whether G-CSF-exposed hematopoietic cells act through circulating and soluble factors, the presence of GCSFR on hematopoietic cells specifically seems to be critical for the observed positive effects on brain repair and function.

With the increasing success of cancer therapies, treatment-associated (long-term) toxicities among cancer survivors pose a challenging problem for patient management (16). Moreover, there are currently no available treatment options for patients who develop radiation-associated structural brain changes (15), and impaired cognition and mood changes are among the most important reasons for treatment-related morbidity and impaired quality of life in cancer patients $(16,51)$. The ability to improve cognitive deficits in patients treated with brain irradiation would be of considerable clinical impact for patients and their families.

Collectively, our findings provide evidence for functionally relevant brain repair following radiation injury and identify an unanticipated connection between bone marrow function and brain plasticity with the potential to develop a clinically relevant brain repair strategy that could be rapidly translated into a clinically available application.

While our data provide evidence that monocyte-macrophage and microglial cell populations are likely to play a major role in our findings, we do not know precisely what bone marrow-derived cells or what product from these cells may affect neural cells and nervous system function; however, the translation potential of this critically relevant mechanism of neural repair using a readily available and clinically widely used cytokine growth factor in patients is noteworthy.

Further, the unanticipated link between the bone marrow and brain shown by this work is an interesting inversion of the prior studies showing how neural cells affect hematopoietic stem/progenitor cells and suggests that further evaluation of the interactions between these tissues may yield novel modes of altering clinical outcomes $(52,53)$.

\section{Methods}

\section{Mice}

G-CSFR $^{-1-}$ (54), Nestin-GFP (55), and UBI-GFP (56) mice (Jackson Laboratory) were described previously. Littermates were used as controls for all experiments involving $\mathrm{G}_{-} \mathrm{CSFR}^{--}$mice. Female B6.SJL-Ptprca Pep3b/BoyJ mice (SJL, CD45.1, Jackson Laboratory) were employed as transplant recipients. Male C57BL/6 mice were used for all behavioral testing experiments. Mice were either irradiated $\left({ }^{137} \mathrm{Cs}\right.$ source) with whole-body radiation at a dose of 4.5 or $9.5 \mathrm{~Gy}$ or received focal brain radiation with a single dose of $4.5 \mathrm{~Gy}$ or 6 Gy or 3 fractionated doses of 2 Gy. For focal brain irradiation, mice were anesthetized using a mixture of Ketamine and Xylazine, and a custom-made lead shield was used (Supplemental Figure 5). Mice were treated with intraperitoneal injections of recombinant human G-CSF (Neupogen, Filgrastrim) at a dose of $250 \mu \mathrm{g} / \mathrm{kg}$. Control mice were injected with PBS alone. In experiments designed to measure BrdU incorporation, mice were treated with intraperitoneal injections of $50 \mathrm{mg} / \mathrm{kg}$ BrdU (MilliporeSigma).

\section{Cell culture}

To isolate cells from brain tissue for in vitro analysis, mice were sacrificed via $\mathrm{CO}_{2}$ asphyxia. Brain tissue was removed and placed in HBSS. Tissue was homogenized with a glass homogenizer. Cells were isolated as previously described (57). The protocol described by DoreDuffy et al. (57) was modified in the following ways: collagenase II incubation was shortened from overnight to 3 hours, and exclusion of small cellular structures by $40-\mu \mathrm{m}$ mesh filtering was omitted. Cells were plated on FN/LN-coated flasks that had been pretreated with fibronectin $(10 \mu \mathrm{g} / \mathrm{ml}$, Millipore) and laminin $(2.5 \mu \mathrm{g} / \mathrm{ml}$, Invitrogen) for at least 24 hours at $4^{\circ} \mathrm{C}$. Neural progenitor medium (EF20) was made by mixing $500 \mathrm{ml}$ Neurobasal Medium (Invitrogen) with 7.5 $\mathrm{ml}$ L-glutamine (Cellgro), 1× B27 supplement (Gibco, Thermo Fisher Scientific), 0.5× N2 supplement (Gibco, Thermo Fisher Scientific), 2 $\mu \mathrm{g} / \mathrm{ml}$ heparin (MilliporeSigma, H3149), 0.5× penicillin/streptomycin (Cellgro), $20 \mathrm{ng} / \mathrm{ml} \mathrm{bFGF,} \mathrm{and} 20 \mathrm{ng} / \mathrm{ml} \mathrm{EGF} \mathrm{(R \& D} \mathrm{Systems).}$ Base medium for other progenitor cells assays was Sato: $500 \mathrm{ml}$ DMEM-F12, $0.3 \mathrm{ml}$ BSA (ICN, 810101), $16.5 \mathrm{mg}$ putrescin (MilliporeSigma), $0.06 \mathrm{~g}$ progesterone (MilliporeSigma), $0.04 \mathrm{~g}$ sodium selenite (MilliporeSigma), $5 \mathrm{mg}$ insulin (MilliporeSigma, I-5500), and $50 \mathrm{mg}$ transferrin (MilliporeSigma) (58). To culture neural progenitors or mesenchymal progenitor cells, Sato was supplemented with bFGF and PDGF.

\section{FACS isolation of perivascular neural progenitor cells from WT mice}

For flow cytometry and FACS, cells were resuspended in modified PBS (0.5\% FBS, 0.5 mM EDTA) and stained for PDGFRB (CD140b)-APC (eBioscience, 17-1402-80) and CD31-FITC (BD Bioscience, 553372). 
A

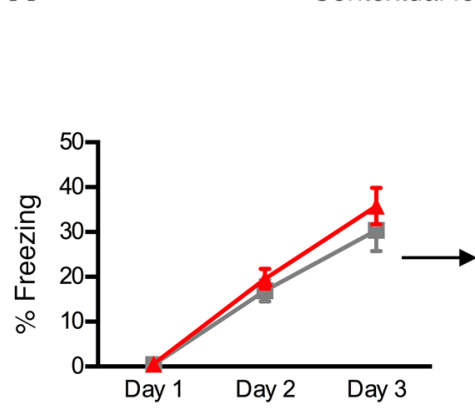

B

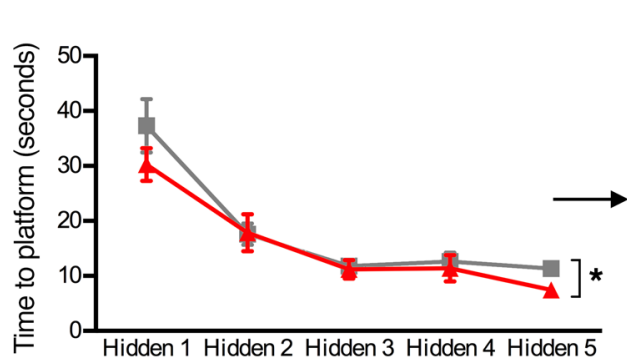

XRT

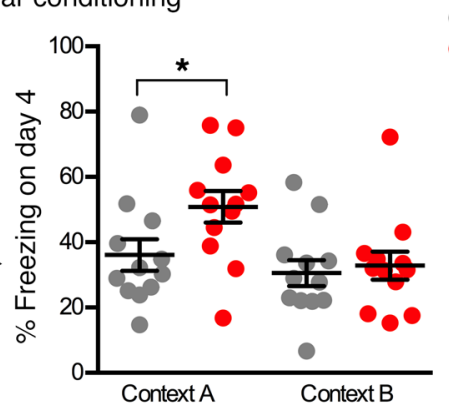

C Total white matter

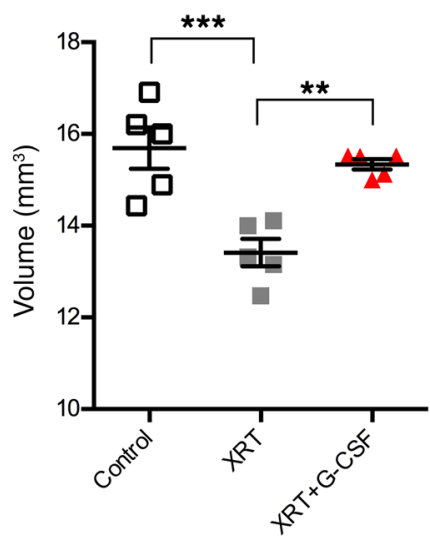

Figure 7. G-CSF improves neurocognitive function and restores cerebral white matter following brain irradiation. Behavioral assessment of mice after fractionated focal brain irradiation ( $3 \times 2$ Gy) followed by G-CSF treatment administered on days 1, 3, 5, 7, 14, and 21 after irradiation. (A) Contextual learning and fear conditioning assay. Time spent "freezing" as a percentage of total time (180 seconds) in shock-associated context A on days 1,2 , and 3 of training (left graph); percentage of time spent freezing on day 4 in context A (conditioned context) and context B (dissimilar context) in the absence of foot shock (right graph). ${ }^{*} P<0.05,2$-way ANOVA. $n=10-12$ independent biological replicates. (B) Morris water maze assay. Mean time (in seconds) for each group to learn and to swim to the hidden platform over 5 successive trial stages (left) and mean time (in seconds) for each group to swim to a hidden platform at a new location over 3 successive trial stages (right). Asterisks indicate significant change relative to control. ${ }^{*} P<0.05,2$-way ANOVA. $n=10-12$ independent biological replicates. (C) MRI segmentation analysis of mice 12-14 months after focal brain irradiation. Quantitative analysis of brain volumes obtained from automated segmentation. Box plots of white matter volume (including CC, external capsule, internal capsule, anterior commissure, and fimbria) indicate a reduction of white matter volume in the group exposed to radiation alone. Both the groups exposed to irradiation with G-CSF and the untreated (nonirradiated) control group have similar white matter volumes with higher median values compared with the radiation-only group. ${ }^{*} P<0.01$; ${ }^{* * *} P<0.001$, Student's $t$ test. $n=5$ independent biological replicates. Data are presented as mean \pm SEM of biological replicates.

FACS and cytometry were performed on a BD FACSAria II sorter, and cells were collected in $1 \mathrm{ml}$ of Sato medium supplemented with PDGF/ bFGF. Cells were positively sorted for $\mathrm{CD}_{140 \mathrm{~b}^{+}}$, and $\mathrm{CD} 31^{+}$cells were subsequently eliminated. Cells were either lysed immediately to obtain mRNA or plated on FN/LN-coated flasks and expanded.

\section{Real-time qPCR}

Cells obtained from FACS were immediately lysed, and mRNA was collected using the Arcturus PicoPure RNA Isolation Kit (Applied Biosystems, KIT0204) per the manufacturer's protocol. Cells in culture were trypsinized, spun down, and lysed using the same kit and procedure. Collected mRNA was reverse transcribed to cDNA using the High-Capacity cDNA Reverse Transcription Kit (Applied Biosystems, 4368814) per the manufacturer's protocol, and qPCR reactions were run using SYBR Green PCR Master Mix (Applied Biosystems, 4309155). Gapdh was used as a reference gene. All reactions were run in triplicate. Primers sequences were as follows: Gapdh, AGGTCGGTGTGAACGGATTTGTGTAGACCATGTAGTTGAGGTCA; Nestin, GGTTGCGTCGGGGAAGAATCCTCCAGGCGTCGATTGAG; $P d g f r-B$, TCCAGGAGTGATACCAGCTTTCAGGAGCCATAACACGGACA; Egf, AGAGCATCTCTCGGATTGACCCCCGTTAAGGAAAACTCTTAGCA; and Pdgf-B, TGCAATAACCGCAATGTGCAAGGGTCACTACTGTCTCACACTT.

\section{Histology, immunofluorescence, and microscopy}

Brain tissue for histology was obtained by sacrificing mice by transcardial perfusion. Briefly, mice were anesthetized with $80 \mathrm{mg} / \mathrm{kg}$ ketamine and $20 \mathrm{mg} / \mathrm{kg}$ xylazine and an incision was made in the chest/abdomen and the diaphragm to reveal the heart. A small incision was made in the right atrium of the heart and a 27-gauge needle was placed in the left ventricle. Approximately $10 \mathrm{ml}$ PBS was injected through the circulation to clear out blood, followed by $10-15 \mathrm{ml}$ of ice-cold $4 \%$ paraformaldehyde (PFA) to fix the tissue. Mice were decapitated and brain tissue was extracted using sterile technique and post-fixed in $4 \%$ PFA for 24 hours at $4^{\circ} \mathrm{C}$. Tissue was then placed in $25 \%$ sucrose for 24 hours for dehydration and embedded in $4 \%$ agar for sectioning. Sections $40 \mu \mathrm{m}$ thick were made on a Leica VT1000S vibratome and stored in $0.02 \%$ sodium azide PBS at $4^{\circ} \mathrm{C}$. Immunohistochemistry was performed as previously described (34). Briefly, sections were washed 3 times in Tris-buffered saline (5 minutes each), blocked with TBS Plus (3\% donkey serum, 0.1\% Triton-X100 in TBS) for 30 minutes at room temperature, and incubated with primary antibody in TBS Plus for 48 hours at $4^{\circ} \mathrm{C}$ on a shaking platform. For BrdU detection, antigen retrieval was performed in $50 \%$ formamide (2 hours at $\left.65^{\circ} \mathrm{C}\right)$ and $2 \mathrm{M} \mathrm{HCL}\left(30\right.$ minutes at $\left.37^{\circ} \mathrm{C}\right)$ prior to blocking. Primary antibodies used were as follows: $\mathrm{BrdU}$ (Abcam, ab6326, dilution 1:500), CD31 (BD Biosciences - Pharmingen, 553370, dilution 1:500), Doublecortin (Abcam, ab18723, dilution: 1:500), GCSFR (R\&D Systems, 
Fab6039A, dilution 1:250), GFP-FITC used to enhance EGFP signal (Abcam, ab6662, dilution 1:1000), F4/80 (Abcam, ab6640, dilution 1:500), GFAP (DAKO, 70334, dilution 1: 1000), Iba-1 (Abcam, ab5076, dilution 1:500), Nestin (Millipore, MAB377, Dilution: 1:250), NeuN (Millipore, MAB353, dilution: 1:250), NG2 (Millipore, MAB5320, dilution: 1:250), B-III tubulin (Chemicon AB9354, 1:1000), and Olig2 (Millipore, AB9610, dilution:1:500). After primary antibody staining, sections were washed in TBS, blocked again in TBS Plus, and incubated with secondary antibody in TBS Plus for 4 hours at room temperature on a shaking platform. Appropriate secondary antibodies used were from Invitrogen's Alexa series and were used at a 1:1000 dilution. Finally, sections were rinsed twice in TBS, incubated with DAPI (Invitrogen, dilution 1:1000) for 5 minutes, rinsed again ( 6 times), and mounted on microscope slides. Sections were covered with ProLong Antifade (Invitrogen). Tissue was viewed under a Nikon Eclipse Ti confocal microscope. Images were collected with NIS-Elements Microscope Imaging Software and optimized and analyzed using ImageJ (NIH) or Adobe Photoshop CS5.

\section{G-CSF ELISA}

Serum for measurement of G-CSF was obtained by cardiac puncture, centrifuged at $4500 \mathrm{~g}$ for 10 minutes at $4^{\circ} \mathrm{C}$, and the G-CSF cytokine measured using mouse G-CSF ELISA (R\&D Systems) according to the manufacturer's instructions.

\section{Structural MRI}

Three groups of mice were imaged using structural MRI at 15T. Structural MRI was obtained with a T1-weighted turbo spin echo sequence $(\mathrm{TR} / \mathrm{TE}=4000 / 5.6 \mathrm{~ms}$, turbo factor 8$)$, in plane field of view 1814.4 $\mathrm{mm}^{2}$, matrix 192'154, 80 slices, slice thickness $180 \mathrm{~mm}$, interleaved acquisition with no slice gap, voxel size of $80^{\prime} 80^{\prime} 180 \mathrm{~mm}^{3}, 8$ averages, acquisition time 12:04 minutes. An elliptical surface coil $\left(2^{\prime} 3 \mathrm{~cm}\right.$, short/long diameters) was used to acquire brain images. A signal to noise (SN) map matched to the structural MRI was acquired to correct for sensitivity profile of the surface coil. Image intensity nonuniformity due to sensitivity profile of the coil was corrected in post-processing.

\section{Image segmentation}

We used a publicly available software tool (59) to automatically segment mouse brains into 20 anatomical structures on each hemisphere. This tool uses a multi-atlas segmentation propagation method in which mouse brain atlases with manually labeled structures are coregistered to the input image and the labels are then fused to generate the final labels. Before segmentation, the images were skull-stripped using Brain Extraction Tool (60) and corrected for intensity nonuniformity using N4ITK algorithm (60) available in Slicer (https://www.slicer.org/).

\section{Bone marrow isolation and transplantation protocol}

Donor mice were sacrificed via $\mathrm{CO}_{2}$ asphyxia; tibiae and femurs were removed and excess soft tissue was eliminated. Using a pestle and mortar, the bones were crushed and washed in PBS with 2\% FBS and passed through a $70-\mu \mathrm{m}$ filter into a collection tube. Cells were spun at $500 \mathrm{~g}$ for 5 minutes; the supernatant was removed, and cells were then subjected to ACK-lysis buffer (Lonza) to remove erythrocytes. All bone marrow transplantations were performed by tail vein injection. Specifically, $2.5 \times 10^{6}$ whole bone marrow cells from $\mathrm{CD} 45.2^{+} \mathrm{G}-\mathrm{CSF}^{\mathrm{KO}}$ or littermate controls were injected into lethally irradiated (9.5 Gy) recipient BL6-SJL (CD45.1 $)$ mice. Engraftment efficiency in recip- ients was monitored by donor contribution of CD $45.2^{+}$cells using FACS analysis and peripheral blood counts. Peripheral blood samples were obtained through retroorbital bleeding 1 to 2 months after bone marrow transplantation. Mice were anesthetized using isoflurane, and blood was collected from the retroorbital venous plexus through a microcapilary-heparinized tube. For GFP transplants, $1 \times 10^{6}$ whole bone marrow cells from UBI-GFP mice were transplanted into wholebody-irradiated or nonirradiated C57BL/6 male recipient mice.

\section{Behavioral testing: tests for anxiety-like and depression-like behaviors} OF tests, EPM, and LDB tests (61) were performed after 1 month and, in some experiments, 4 months following irradiation.

OF test. Mice were placed in a corner of Plexiglas boxes $(41 \mathrm{~cm}$ wide $\times 41 \mathrm{~cm}$ long $\times 38 \mathrm{~cm}$ high) equipped with 32 infrared photobeams (SmartFrame Open Field System; Kinder Scientific) to track $x-y$ ambulatory movements and rearing events. The activity chambers were computer interfaced for data collection and postprocessing analysis using MotorMonitor Software (Kinder Scientific). Testing took place under bright lighting conditions (700 lux). Activity was recorded for 30 or 60 minutes. The apparatus was cleaned with water and $70 \%$ alcohol between trials. Exploratory activity was measured using total distance traveled (in centimeters) and the number of rearing events. Anxiety-like behavior was assessed using number of entries into the center of the arena and the percentage of distance traveled (in $\mathrm{cm}$ ) and time spent (in seconds) in the center (62).

$E P M$. The plus maze used consisted of 4 black Plexiglas arms that formed a cross shape, with 2 open arms $(67 \times 7 \mathrm{~cm})$ opposite each other and 2 enclosed arms $(67 \times 7 \times 17 \mathrm{~cm})$ perpendicular to the open arms. The maze was $55 \mathrm{~cm}$ above the floor. Mice were brought into the experimental room individually and placed in the center of the maze facing an enclosed arm. Animals were allowed to explore the apparatus for 5 minutes, and activity was recorded. The apparatus was cleaned with water and $70 \%$ alcohol between trials. Number of entries into open and enclosed arms as well as time spent in open and enclosed arms was recorded. Anxiety-like behavior was assessed by comparing number of entries into all arms, percentage of entries into open arms, and percentage of time spent in open arms.

LDB test. The apparatus used for the OF test (described above) was also used for the LDB test. Dark and light compartments were defined by covering one-half of the chamber with a dark plastic box that is opaque to visible light, but transparent to infrared. An opening on the bottom-center of the wall separating the 2 compartments allowed mice to freely move between them. The light compartment was brightly illuminated (700 lux). Mice were placed in a corner of the dark compartment and allowed to explore both compartments for 10 minutes. The apparatus was cleaned with water and $70 \%$ ethanol between trials. Anxiety-like behavior was assessed by comparing latency to enter the light compartment as well as percentage of time spent (in seconds) and distance covered (in $\mathrm{cm}$ ) in the light compartment.

\section{Behavioral testing: tests for learning and memory}

Contextual fear discrimination learning. Mice were tested 6 weeks following irradiation. Fear conditioning was conducted in conditioning chambers $(18 \mathrm{~cm}$ wide $\times 18 \mathrm{~cm}$ long $\times 30 \mathrm{~cm}$ high $)$ with a clear Plexiglas wall and ceiling, 3 metal walls, and a stainless steel grid floor (Coulbourn Instruments). The conditioning chambers were placed inside ventilated, sound-dampening isolation chambers (Coulbourn Instruments) and lit by house lights mounted on one wall. Mice were allowed to accli- 
mate to the test room for an hour before testing. Animal behavior was recorded using video cameras mounted on the chamber ceiling. FreezeFrame and FreezeView software (Actimetrics) were used for recording and analyzing freezing behavior, respectively. For the shock-associated training context A, the house fan and lights were switched on, stainless steel grids were exposed, and silver wall panels were used. For the similar yet different context $\mathrm{B}$, the stainless steel grid floor was covered with a cardboard panel and wood-chip bedding, black wall panels were used, $15-\mathrm{cm}$ high curved green plastic inserts covered the bottom half of the walls, and the house fan and lights were turned off. The chamber door was left ajar during testing in context $\mathrm{B}$, and white noise was delivered through built-in speakers for the duration of the testing. Water and $70 \%$ ethanol were used to clean grids and drop pan between trials in context $\mathrm{A}$, and the bedding was changed between trials in context $\mathrm{B}$. Animals were trained for 3 days in context A by delivering a single 2-second foot shock of $0.75 \mathrm{~mA}, 180$ seconds following placement of the mouse in the training context. The mouse was taken out 15 seconds following termination of the foot shock and returned to its home cage. On day 4, mice were randomly assigned to 2 groups: one group was first tested in context $\mathrm{A}$ and then again in context $\mathrm{B}$, while the other group was tested in context B and then A. Mice were allowed to rest for a minimum of 3 hours between tests. No shocks were delivered on day 4 . Freezing behavior of animals in both training context A (180 seconds preshock only) and context B was used to assess discrimination between the 2 contexts. The discrimination ratio was computed as follows: (freezing in training context - freezing in similar context)/(freezing in training context + freezing in similar context). A score of 0 indicates complete lack of discrimination (freezing level is the same in both contexts), whereas a score of 1 indicates perfect discrimination (no freezing behavior exhibited in a similar context). Only males were used for these experiments.

\section{Morris water maze task}

Mice were trained in the reference memory version of the Morris water maze task (63). A transparent escape platform was placed in a circular pool (1.89 m diameter) with 4 distinct visual cues placed at north, south, east, and west. Water was maintained at room temperature $\left(20-25^{\circ} \mathrm{C}\right)$. The task consisted of 4 phases: hidden platform in north-west quadrant (3 stages on day 1, 2 stages on day 2), visible platform marked with red tape and placed $0.5 \mathrm{~cm}$ above water level (1 stage on day 2$)$, probe with the platform removed ( 1 trial on day 2 ), and reversal with the platform hidden in south-east quadrant (3 stages on day 3). Each stage consisted of 4 trials. Each trial was started at 1 of 4 possible start locations such that a start location was never repeated within the same stage or on consecutive trials. Mice were allowed to swim for a maximum of 120 seconds, with the exception of the probe trial, which lasted 60 seconds. If a mouse was unable to find the platform in 120 seconds, it was guided to the platform by its tail. Mice were required to stay on the platform for a minimum of 3 seconds before a trial ended. ANY-maze software (Stoelting) was used to measure latency to platform, time spent in each quadrant, swim path length, and swim speeds. These parameters were used to assess general spatial learning. The reversal phase was repeated at 13 weeks following irradiation, with the platform in south-west quadrant, and again at 45 weeks following irradiation, with the platform in south-west quadrant. Only males were used for these experiments.

\section{Statistics}

Statistical analysis was carried out using Prism software. Statistical significance was assessed by unpaired 2-tailed Student's $t$ tests when comparing 2 groups and ANOVA when comparing more than 2 groups. Significant main effects or interactions were followed up with Bonferroni's correction or Tukey's post hoc tests, where appropriate.

\section{Study approval}

All animal experiments were performed in accordance with national and institutional guidelines. All procedures were approved by the MGH Internal Animal Care and Use Committee. Mice were housed in the MGH Animal Research Facility on a 12-hour light/12-hour dark cycle with stable temperature $\left(22^{\circ} \mathrm{C}\right)$ and humidity $(60 \%)$.

\section{Author contributions}

JD and NB designed and conducted the experiments, analyzed the data, and wrote the manuscript. NN, IL, YV, and BY conducted experiments and helped with data analysis. TTB, AB, KUG, and NS assisted and provided guidance on data analysis. AS provided guidance and oversaw the design, conduct, and analysis of neurobehavioral studies. OCA conducted magnetic imaging studies and provided data analysis on imaging studies. DS oversaw the project and contributed to design, analysis, and writing of the manuscript.

\section{Acknowledgments}

The authors gratefully acknowledge support from an Institutional Research Grant from the American Cancer Society (to JD). JD is a recipient of an American Academy of Neurology (AAN) Clinical Research Training Fellowship (CRTF). This work also has been made possible through philanthropic support from the Amy Gallagher Foundation, generous donations from the R. Tawil and S. McPhee family foundations, and the Gerald and Darlene Jordan Chair in Medicine (to DTS). NB is supported by grants from The Swedish Childhood Cancer Foundation and The Swedish Research Council. DTS is supported by the NIH, Ludwig Cancer Research, and the Harvard Stem Cell Institute. We also thank Jing Wang and Kourosh Jafari-Khouzani at Harvard Medical School for analyzing the MRI data, Lauren Geisel for technical support of behavioral assays, and Mike Whalen for assistance with the Morris water maze assay.

Address correspondence to: David T. Scadden, 185 Cambridge Street, Boston, Massachusetts 02114, USA. Phone: 617.726.5615; Email: david_scadden@harvard.edu. Or to: Jorg Dietrich, MGH Cancer Center, 55 Fruit Street, Yawkey 9E, Boston, Massachusetts 02114, USA. Phone: 617.724.8770; Email: Dietrich.Jorg@mgh.harvard.edu.

\footnotetext{
1. Sawada M, Matsumoto M, Sawamoto K. Vascular regulation of adult neurogenesis under physiological and pathological conditions. Front Neurosci. 2014;8:53.

2. Palmer TD, Willhoite AR, Gage FH. Vascular niche for adult hippocampal neurogenesis.
}

JComp Neurol. 2000;425(4):479-494.

3. Jessberger S, Gage FH. Adult neurogenesis: bridging the gap between mice and humans. Trends Cell Biol. 2014;24(10):558-563.

4. Boulanger JJ, Messier C. From precursors to myelinating oligodendrocytes: contribution of intrinsic and extrinsic factors to white matter plasticity in the adult brain. Neuroscience. 2014;269:343-366.

5. Bercury KK, Macklin WB. Dynamics and mechanisms of CNS myelination. Dev Cell. 2015;32(4):447-458.

6. Dimou L, Götz M. Glial cells as progenitors and 
stem cells: new roles in the healthy and diseased brain. Physiol Rev. 2014;94(3):709-737.

7. Hughes EG, Kang SH, Fukaya M, Bergles DE. Oligodendrocyte progenitors balance growth with self-repulsion to achieve homeostasis in the adult brain. Nat Neurosci. 2013;16(6):668-676.

8. Xing YL, et al. Adult neural precursor cells from the subventricular zone contribute significantly to oligodendrocyte regeneration and remyelination. J Neurosci. 2014;34(42):14128-14146.

9. Yao J, Mu Y, Gage FH. Neural stem cells: mechanisms and modeling. Protein Cell. 2012;3(4):251-261.

10. Monje ML, Mizumatsu S, Fike JR, Palmer TD. Irradiation induces neural precursor-cell dysfunction. Nat Med.2002;8(9):955-962.

11. Rola R, et al. Radiation-induced impairment of hippocampal neurogenesis is associated with cognitive deficits in young mice. Exp Neurol. 2004;188(2):316-330.

12. Monje M, Dietrich J. Cognitive side effects of cancer therapy demonstrate a functional role for adult neurogenesis. Behav Brain Res. 2012;227(2):376-379.

13. Hellström NA, Björk-Eriksson T, Blomgren K, Kuhn HG. Differential recovery of neural stem cells in the subventricular zone and dentate gyrus after ionizing radiation. Stem Cells. 2009;27(3):634-641.

14. Kumar M, Haridas S, Trivedi R, Khushu S, Manda K. Early cognitive changes due to whole body $\gamma$ irradiation: a behavioral and diffusion tensor imaging study in mice. Exp Neurol. 2013;248:360-368.

15. Prust MJ, et al. Standard chemoradiation for glioblastoma results in progressive brain volume loss. Neurology. 2015;85(8):683-691.

16. Dietrich J, Monje M, Wefel J, Meyers C. Clinical patterns and biological correlates of cognitive dysfunction associated with cancer therapy. Oncologist. 2008;13(12):1285-1295.

17. Dietrich J, Wen P. Neurologic complications of chemotherapy. In: Schiff D, Kesari S, Wen P, eds. Cancer Neurology in Clinical Practice. Totowa, New Jersey: Humana Press Inc.; 2008:287-326.

18. Bendall LJ, Bradstock KF. G-CSF: From granulopoietic stimulant to bone marrow stem cell mobilizing agent. Cytokine Growth Factor Rev. 2014;25(4):355-367.

19. Welte K. G-CSF: filgrastim, lenograstim and biosimilars. Expert Opin Biol Ther. 2014;14(7):983-993.

20. Hopman RK, DiPersio JF. Advances in stem cell mobilization. Blood Rev. 2014;28(1):31-40.

21. Schneider A, et al. The hematopoietic factor $\mathrm{G}-\mathrm{CSF}$ is a neuronal ligand that counteracts programmed cell death and drives neurogenesis. JClin Invest. 2005;115(8):2083-2098.

22. Diederich K, et al. Synergetic effects of granulocyte-colony stimulating factor and cognitive training on spatial learning and survival of newborn hippocampal neurons. PLoS One. 2009;4(4):e5303.

23. London A, et al. Neuroprotection and progenitor cell renewal in the injured adult murine retina requires healing monocyte-derived macrophages. J Exp Med. 2011;208(1):23-39.

24. Tanaka R, et al. Migration of enhanced green fluorescent protein expressing bone marrow-derived microglia/macrophage into the mouse brain following permanent focal ischemia. Neuroscience. 2003;117(3):531-539.

25. Gliem M, et al. Macrophages prevent hemorrhag- ic infarct transformation in murine stroke models. Ann Neurol. 2012;71(6):743-752.

26. Shechter $\mathrm{R}$, et al. Infiltrating blood-derived macrophages are vital cells playing an anti-inflammatory role in recovery from spinal cord injury in mice. PLoS Med. 2009;6(7):e1000113.

27. Orlic $D$, et al. Bone marrow cells regenerate infarcted myocardium. Nature. 2001;410(6829):701-705.

28. Dutta $P$, et al. Myocardial infarction activates CCR2(+) hematopoietic stem and progenitor cells. Cell Stem Cell. 2015;16(5):477-487.

29. Krause DS, et al. Multi-organ, multi-lineage engraftment by a single bone marrow-derived stem cell. Cell. 2001;105(3):369-377.

30. Wagers AJ, Sherwood RI, Christensen JL, Weissman IL. Little evidence for developmental plasticity of adult hematopoietic stem cells. Science. 2002;297(5590):2256-2259.

31. Svendsen CN, Bhattacharyya A, Tai YT. Neurons from stem cells: preventing an identity crisis. Nat Rev Neurosci. 2001;2(11):831-834.

32. Sahay $\mathrm{A}$, et al. Increasing adult hippocampal neurogenesis is sufficient to improve pattern separation. Nature. 2011;472(7344):466-470.

33. Garthe A, Kempermann G. An old test for new neurons: refining the Morris water maze to study the functional relevance of adult hippocampal neurogenesis. Front Neurosci. 2013;7:63.

34. Dietrich J, Han R, Yang Y, Mayer-Pröschel M, Noble M. CNS progenitor cells and oligodendrocytes are targets of chemotherapeutic agents in vitro and in vivo. J Biol. 2006;5(7):22.

35. Arrillaga-Romany IC, Dietrich J. Imaging findings in cancer therapy-associated neurotoxicity. Semin Neurol. 2012;32(4):476-486.

36. Bertani N, Malatesta P, Volpi G, Sonego P, Perris R. Neurogenic potential of human mesenchymal stem cells revisited: analysis by immunostaining, time-lapse video and microarray. JCell Sci. 2005;118(Pt 17):3925-3936.

37. Kodama H, et al. Neurogenic potential of progenitors derived from human circulating $\mathrm{CD} 14+$ monocytes. Immunol Cell Biol. 2006;84(2):209-217.

38. Tondreau T, et al. Bone marrow-derived mesenchymal stem cells already express specific neural proteins before any differentiation. Differentiation. 2004;72(7):319-326.

39. Woodbury D, Reynolds K, Black IB. Adult bone marrow stromal stem cells express germline, ectodermal, endodermal, and mesodermal genes prior to neurogenesis. J Neurosci Res. 2002;69(6):908-917.

40. Parihar VK, Limoli CL. Cranial irradiation compromises neuronal architecture in the hippocampus. Proc Natl Acad Sci U S A. 2013;110(31):12822-12827.

41. Nokia MS, Anderson ML, Shors TJ. Chemotherapy disrupts learning, neurogenesis and theta activity in the adult brain. Eur J Neurosci. 2012;36(11):3521-3530.

42. Clelland CD, et al. A functional role for adult hippocampal neurogenesis in spatial pattern separation. Science. 2009;325(5937):210-213.

43. Deng W, Aimone JB, Gage FH. New neurons and new memories: how does adult hippocampal neurogenesis affect learning and memory? Nat Rev Neurosci. 2010;11(5):339-350.

44. Kempermann G. The neurogenic reserve hypoth- esis: what is adult hippocampal neurogenesis good for? Trends Neurosci. 2008;31(4):163-169.

45. Burgess N, Maguire EA, O'Keefe J. The human hippocampus and spatial and episodic memory. Neuron. 2002;35(4):625-641.

46. Knoth R, et al. Murine features of neurogenesis in the human hippocampus across the lifespan from 0 to 100 years. PLoS One. 2010;5(1):e8809.

47. Squire LR, Ojemann JG, Miezin FM, Petersen SE, Videen TO, Raichle ME. Activation of the hippocampus in normal humans: a functional anatomical study of memory. Proc Natl Acad Sci U S A. 1992;89(5):1837-1841.

48. Ekstrom $\mathrm{AD}$, et al. Cellular networks underlying human spatial navigation. Nature. 2003;425(6954):184-188

49. Richard GR, Titiz A, Tyler A, Holmes GL, Scott RC, Lenck-Santini PP. Speed modulation of hippocampal theta frequency correlates with spatial memory performance. Hippocampus. 2013;23(12):1269-1279.

50. Kim JS, et al. Granulocyte-colony stimulating factor ameliorates irradiation-induced suppression of hippocampal neurogenesis in adult mice. Neurosci Lett. 2010;486(1):43-46.

51. Taphoorn MJ, Klein M. Cognitive deficits in adult patients with brain tumours. Lancet Neurol. 2004;3(3):159-168

52. Méndez-Ferrer S, Lucas D, Battista M, Frenette PS. Haematopoietic stem cell release is regulated by circadian oscillations. Nature. 2008;452(7186):442-447.

53. Méndez-Ferrer S, et al. Mesenchymal and haematopoietic stem cells form a unique bone marrow niche. Nature. 2010;466(7308):829-834.

54. Liu F, Wu HY, Wesselschmidt R, Kornaga T, Link DC. Impaired production and increased apoptosis of neutrophils in granulocyte colony-stimulating factor receptor-deficient mice. Immunity. 1996;5(5):491-501.

55. Mignone JL, Kukekov V, Chiang AS, Steindler D, Enikolopov G. Neural stem and progenitor cells in nestin-GFP transgenic mice. J Comp Neurol. 2004;469(3):311-324.

56. Schaefer BC, Schaefer ML, Kappler JW, Marrack $\mathrm{P}$, Kedl RM. Observation of antigen-dependent CD8+ T-cell/ dendritic cell interactions in vivo. Cell Immunol. 2001;214(2):110-122.

57. Dore-Duffy P. Isolation and characterization of cerebral microvascular pericytes. Methods Mol Med. 2003;89:375-382.

58. Dietrich J, Noble M, Mayer-Proschel M. Characterization of A2B5+ glial precursor cells from cryopreserved human fetal brain progenitor cells. Glia. 2002;40(1):65-77.

59. Ma D, et al. Automatic structural parcellation of mouse brain MRI using multi-atlas label fusion. PLoS One. 2014;9(1):e86576.

60. Smith SM. Fast robust automated brain extraction. Hum Brain Mapp. 2002;17(3):143-155.

61. File SE, Baldwin HA. Effects of beta-carbolines in animal models of anxiety. Brain Res Bull. 1987;19(3):293-299.

62. Prut L, Belzung C. The open field as a paradigm to measure the effects of drugs on anxiety-like behaviors: a review. Eur JPharmacol. 2003;463(1-3):3-33.

63. Morris R. Developments of a water-maze procedure for studying spatial learning in the rat. JNeurosci Methods. 1984;11(1):47-60. 